\title{
Successful Colonoscopic Removal of Missed Copper-T
}

\author{
Parveen Malhotra*, Vani Malhotra, Isha Pahuja, Naveen Malhotra, Smiti Nanda and Vandana Bhuriya \\ Department of Medical Gastroenterology, Gynaecology \& Obstetrics and Anesthesiology, India
}

Submission: January 01, 2019; Published: March 07, 2019

*Corresponding author: Parveen Malhotra, Department of Medical Gastroenterology, Gynaecology \& Obstetrics and Anesthesiology, India

\begin{abstract}
Introduction: Intrauterine devices (IUDs) are among the most common contraceptive methods in the world but have been associated with a number of health risks like infection, uterine bleed, ectopic pregnancy and uterine perforation necessitating surgical removal of the IUD.

Observation: A 28-year old woman presented to gynecology department with the complaint of missing threads of IUD which was inserted three years back. She was investigated with Ultrasonography and Contrast Computed Tomography abdomen and pelvis which revealed that uterus was empty, and IUD was seen embedded in distal sigmoid colon.

Results: Patient was admitted for proper evaluation under Medical Gastroenterology department. Informed consent was taken explaining the risk of the procedure and patient was prepared for colonoscopic removal of IUD. During the procedure, an entangled IUD was visualized in sigmoid colon. As it was embedded in colonic wall, it was slowly and gently removed with a foreign body forceps successfully. It is one of rare case report where successful removal of IUD has been done Colonoscopically.
\end{abstract}

Keywords: Intrauterine devices; Colonoscopy; Computed tomography; Colonoscopically; Ectopic pregnancy; Perforation; Gynecology department; Uterine perforation; Ultrasonography; Contrast computed; Gastroenterology; Sigmoid colon

\section{Introduction}

Intrauterine devices (IUDs) are among the most common contraceptive methods in the world but have been associated with a number of health risks like infection, uterine bleed, ectopic pregnancy and uterine perforation necessitating surgical removal of the IUD. Uterine perforation is the most serious complication of the IUD occurring in 1.6 per 1000 insertions [1]. Perforation of IUD may occur either immediately by improper insertion or years after insertion by device migration. In spite of several reports on involvement of the colon by a lost IUD, removal of them by colonoscopy has rarely been reported.

\section{Case Report}

A 28-year old woman presented to gynecology department with the complaint of missing threads of IUD which was inserted three years back at some peripheral health unit after her second delivery. Her menstrual cycles were regular, and she gave history of dysmenorrhea for which she wanted her IUD removal. She went to same center for follow-up of her IUD. Threads were not visualized, and she was referred to some private clinic where she was investigated with Ultrasonography and Contrast Computed Tomography abdomen and pelvis which revealed that uterus was empty, and IUD was seen embedded in distal sigmoid colon. Patient was admitted for proper evaluation under Medical Gastroenterology department. Informed consent was taken ex plaining the risk of the procedure and patient was prepared for colonoscopic removal of IUD.

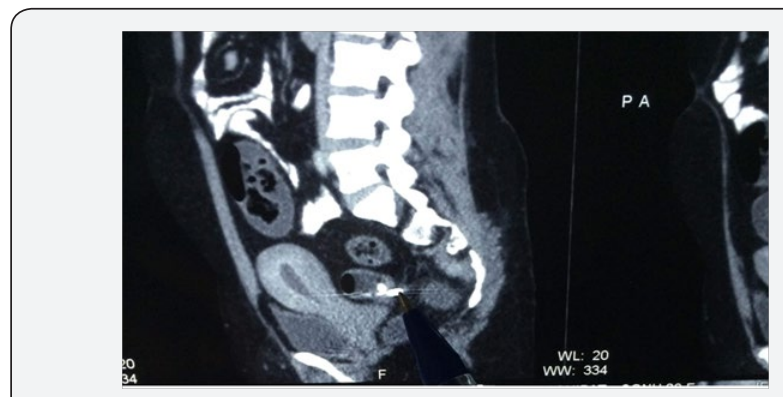

Figure 1:Computed tomograph scan showing embedded copper-T in sigmoid colon

During the procedure, an entangled IUD was visualized in sigmoid colon. As it was embedded in colonic wall, it was slowly and gently removed with a foreign body forceps successfully. Antibiotics were prescribed and patient was kept under close observation for signs of peritonitis for next twenty-four hours. After twenty-four hours, a plain X-ray was performed to rule out air under diaphragm. Patient was initially kept on liquid diet and switched over to full diet. Her post colonoscopic period was uneventful and she was discharged after 72 hours (Figure 1). 


\section{Discussion}

IUDs are widely used as reversible method of contraception preferred due to long duration of birth control effect and ease of use. However, it also has some serious complications such as perforation of the uterus and its migration to the abdominopelvic structures [2]. Risk factors include a retroverted uterus and insertion postpartum during lactation as the uterine wall is thin $[3,4]$. Perforation usually occurs upon insertion however, the IUDs can become embedded in the uterus and later be forced through the wall by uterine contractions into the pelvic or abdominal cavity or into adjacent organs such as the bladder, recto sigmoid and even appendix [5]. Most perforations are asymptomatic and therefore unrecognized at the time of insertion and may not be recognized at the time of insertion and may not be recognized until years later. Intraperitoneal devices could entail severe morbidity such as bowel obstruction, perforation, abscess and fistula [6].

The triad of abdominal pain, fever and intermittent diarrhoea associated with a missing IUD has been suggested as representing the signs and symptoms of bowel injury [7]. Vaginal sonography and other diagnostic tests are necessary to determine if IUD is not contained by the endometrial cavity. X-ray and Computed Tomography scan of the abdomen and pelvis can be useful for diagnosis. World Health Organization recommended removal of dislocated IUD as soon as possible irrespective of their type and location [8].

It is advisable to retrieve a migrated IUD by minimally invasive techniques [9]. Endoscopic techniques such as colonoscopy, hysteroscopy and Cystoscopy can be used for diagnosis and treatment depending on the location of IUD (Figure 2).

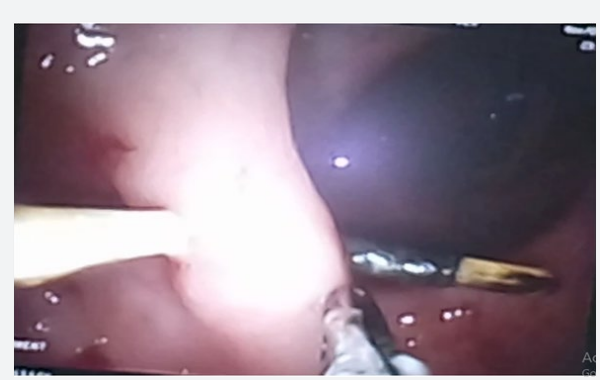

Figure 2: Colonoscopic view of embedded copper-T in sigmoid colon.

\section{Conclusion}

Those patients in whom IUD's are used as contraceptive should always be advised for taking immediate consultation on any suspicion of displacement of IUD, so that necessary action can be taken. Colonoscopically removal can be tried after ruling out possibility of perforation due to displaced IUD. Even after successful removal of IUD Colonoscopically, patient should be observed for next one day to rule out any perforation (Figure 3).

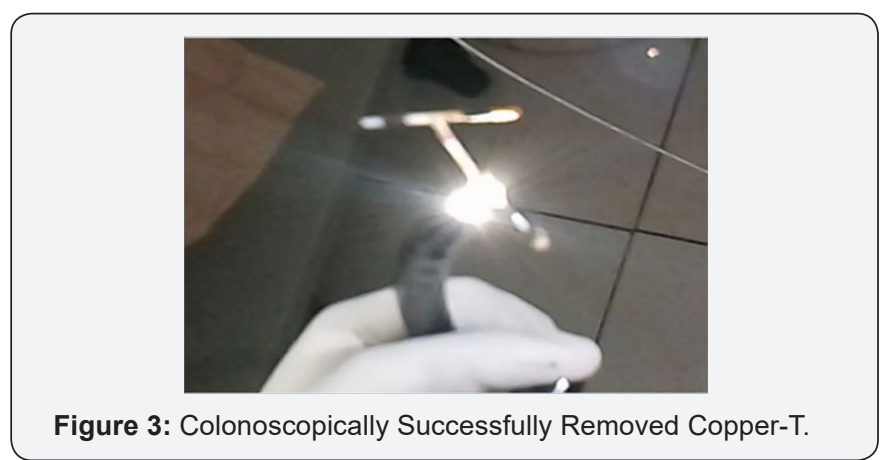

\section{References}

1. Harrison-Woolrych M, Ashton J, Coulter D (2003) Uterine perforation on intrauterine device insertion: is the incidence higher than previously reported? Contraception 67(1): 53-56.

2. Weerasekra A, Wijesinghe P, Nugaduwa W (2014) Sigmoid colocolic fistula caused by intrauterine device migration: a case report. J Med Case Rep 8: 81.

3. Andersson K, Ryde-Blomquist E, Lindell K, Odlind V, Milsom I (1998) Perforations with intrauterine devices: report from a Swedish Survey. Contraception 57(4): 251-255.

4. Dean G, Goldberg A The intrauterine contraceptive device.

5. Carson S, Gatlin A, Mazur M (1981) Appendiceal perforation by Copper-7 intrauterine contraceptive device. Am J Obstet Gynecol 141(5): 586-587.

6. Key TC, Kreutner AK (1980) Gastrointestinal complications of modern intrauterine devices. Obstet Gynecol 55(2): 239-244.

7. Chi E, Rosenfeld D, Sokol T (2005) Laparoscopic removal of an intrauterine device perforating the sigmoid colon: a case report and review of the literature. Am Surg 71(12): 1055-1057.

8. (1987) World Health Organisation (WHO), Mechanism of action, safety and efficacy of intrauterine devices. WHO Technical Report 753, Geneva, Switzerland.

9. Mosley FR, Shahi N, Kurer MA (2012) Elective surgical removal of migrated intrauterine contraceptive devices from within the peritoneal cavity: a comparison between open and laparoscopic removal. JSLS 16(2): 236-242. 
This work is licensed under Creative Commons Attribution 4.0 License

DOI: 10.19080/ARGH.2019.12.555841
Your next submission with JuniperPublishers will reach you the below assets

- Quality Editorial service

- Swift Peer Review

- Reprints availability

- E-prints Service

- Manuscript Podcast for convenient understanding

- Global attainment for your research

- Manuscript accessibility in different formats

( Pdf, E-pub, Full Text, audio)

- Unceasing customer service

Track the below URL for one-step submission https://juniperpublishers.com/online-submission.php 